\title{
CHITOSAN: A REVIEW ON ITS VARIED NOVEL THERAPEUTIC AND INDUSTRIAL APPLICATIONS
}

\section{Krishnaveni B}

Ph.D Research Scholar, Department of Biotechnology, Maharaja Co-education Arts and Science College, Perundurai, Erode, India-52.

Email: krishnavenibt88@gmail.com

\section{ABSTRACT}

Chitosan and its nanoparticles, which are being studied extensively to understand their varied and unique functional properties, have attracted considerable interest due to their biological activities and potential applications in the food, pharmaceutical and environmental industries. This review focuses on the biological activities of Chitosan and its nanoparticles, based on others' latest research results, including antitumor and anticancer effects, antimicrobial, wound healing activities, food preservative and so on, which are all correlated with their structural and physiological properties. The objective of this review is to give in-depth and comprehensive insights into the functionality of chitosan and its nanoparticles and a study of their inherent industrial and therapeutic applications.

Key words: Chitosan, nanoparticles, wound healing, antitumor, antimicrobial

Article Info

Received 09 Aug 2016; Review Completed 04 Nov 2016; Accepted 11 Nov 2016, Available online 15 Nov 2016

URI: http://jddtonline.info/index.php/jddt/article/view/1328

Cite this article as: Krishnaveni B, Chitosan: a review on its varied novel therapeutic and industrial applications, Journal of Drug Delivery \& Therapeutics. 2016; 6(6):70-79 DOI: http://dx.doi.org/10.22270/jddt.v6i6.1328

\section{INTRODUCTION}

Chitosan and its derivatives are examples of valueadded materials. They are produced from chitin, which is a natural carbohydrate polymer found in the skeleton of crustaceans, such as crab, shrimp and lobster, as well as in the exoskeleton of marine zooplankton spp., including coral and jellyfishes ${ }^{1}$. Insects, such as butterflies and ladybugs, also have chitin in their wings and the cell walls of yeast, mushrooms and other fungi also contain this substance ${ }^{2}$. Chitosan (Fig.1) is a polymer obtained from deacetylation of chitin ${ }^{3}$, is a cationic polysaccharide with linear chain cons is ting of B - (1,4)-linked 2-acetamino-2-deoxy - B-D-glucopyranose and 2-amino-2deoxy-ß-D-glucopyranose ${ }^{4}$. Chitosan are used in dietary supplements, water treatment, food preservation, agriculture, cosmetics, pulp \& paper and medicinal application ${ }^{5}$.

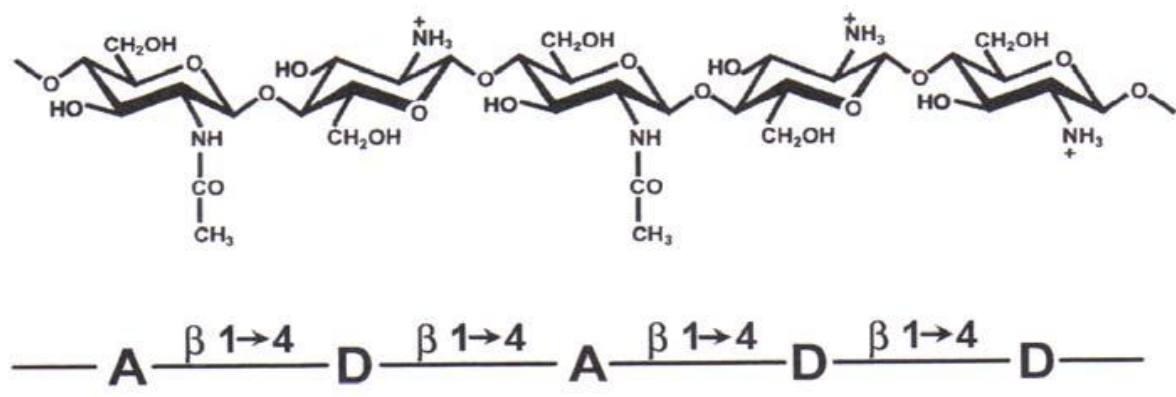

Figure 1: Chemical structure of a partially de- $N$-acetylated chitosan 
There has been a large increase in chitosan research during the past decade. This is due to its biocompability, biodegradability, non-toxicity, and other unique properties such as film forming ability, chelation and adsorption properties and antimicrobial activity ${ }^{6}$. The functional properties of chitosan are reported to be dependent on its molecular weight or viscosity ${ }^{7}$. Earlier investigations demonstrated that chitosans with higher molecular weight (or viscosity) were more effective as food preservatives than those with lower molecular weight ${ }^{8}$. Due to its polycationic nature, chitosan can be used as flocculating agent and act as chelating agent and heavy metal trapper ${ }^{5}$. Chitosan has antibacterial activity ${ }^{9}$ which can be prepared in the form of film or hydro-gel 10,11 to be used in burn and wound dressing and also for fabricating suturing threads ${ }^{12}$. Zahed Hossain et al. reported ${ }^{13}$ the preparation of chitin from shrimp shells and the common procedure for isolating chitin from shrimp shell involves demineralization, deproteinization and decoloration. Industrially, chitosan are normally prepared by alkaline de-N-acetylation of chitin ${ }^{14}$. Due to its simplicity, relative instrument availability, and independence of sample solubility, IR spectroscopy is one of the most studied methods for characteristics of chitin and chitosan ${ }^{15}$.

These polysaccharides are found in a wide range of natural sources, such as crustaceans, insects annelids, molluscs, coelenterates and is a common constituent of fungal cell walls ${ }^{16-18}$. Recent advances in fermentation technologies suggest that the cultivation of selected fungi can provide an alternative source of chitin and chitosan. The amount of these polysaccharides depends of the fungi species and culture conditions 19${ }^{21}$.Filamentous fungi have been considered an attractive source of chitin and chitosan for industrial applications because their specific products can be manufactured under standardized conditions ${ }^{22,23}$. Usually, the Zygomycetes Class has higher amounts of chitin and chitosan in their cell walls when compared to other classes of fungi ${ }^{18,24}$.

The use of biomass from fungi has demonstrated great advantages, such as: independence of seasonal factor, wide scale production, simultaneous extraction of chitin and chitosan, extraction process is simple and cheap resulting in reduction in time and cost required for production, and also absence of proteins contamination, mainly the proteins that could cause allergy reactions in individuals with shellfish allergies $24-27$. However, to optimize the production of chitin and chitosan from fungi, it's usually used complex or synthetics cultures media, which are expensive. It's becomes necessary to obtain economic culture media that promote the growth of fungi and stimulate the production of the polymers.

Table 1: Fungal Cell Wall Major Ingredients

\begin{tabular}{|c|c|c|}
\hline Taxonomic group & Fibrillar polymers & Matrix polymers \\
\hline Oomycetes & $\beta(1,3), \beta(1,6)$ - Glucan; cellulose & Glucan \\
\hline Chytridomycetes & Chitin; glucan & Plucan \\
\hline Zygomycetes & Chitin; chitosan & $\alpha(1,3)$-glucan; xylomannoproteins \\
\hline Basidiomycetes & Chitin; $\beta(1,3)-\beta(1,6)$ glucans & $\alpha(1,3)$-glucan; glucuronomannoproteins \\
\hline Ascomycetes/ deuteromycetes & Chitin; $\beta(1,3)-\beta(1,6)$ glucans & \\
\hline
\end{tabular}

Chitosan and chitooligosaccharides have attracted considerable interest due to their biological activities, namely, antimicrobial, hypocholesterolemic, immunityenhancing and antitumor effects, drug delivery and accelerating Calcium and Ferrum absorption and so on. Studies on the biological activities of chitosan and its oligomers have been increasing, as no single type of chitosan or its oligomers exerts all of the above bioactivities. Moreover, different chitosan derivatives and enzymatic products have different structures and physicochemical properties, which may result in novel bioactivities or novel findings in known bioactive compounds ${ }^{28-31}$.

\section{ANTITUMOR ACTIVITY OF CHITOSAN}

Cancer remains to be one of the leading causes of death worldwide. Over the past several decades' significant advancements have been made in fundamental understanding of cancer biology, which has in turn lead to better diagnostic and treatment methods. A major reason for this is our inability to administer therapeutic agents selectively to the targeted sites without adverse effects on healthy tissue. Current therapeutic strategies for most cancers involve a combination of surgical resection, radiation therapy, and chemotherapy ${ }^{32}$.

Conventional chemotherapy can wreak havoc on healthy tissue, causing painful side effects, and it's not always effective. At the same time, there is the huge risk that the drugs entering the body could also possibly kill the healthy cells near the affected region. This is mainly because the drugs can not differentiate cancer cells from the others and also have some disadvantages for the delivery of conventional drug ${ }^{33}$.

\section{The disadvantages of conventional drug to treat} cancer-

- Within the stroma of tumour cells, the interstitial space separates tumour cells and blood vessels. This distance cannot be crossed by the conventional anticancer drugs.

- Because of poor blood supply to tumour cells, the concentration of drug reaching tumour cells is decreased.

- Due to the absence of lymphatic network the development of high pressure gradient in the 
interstitial space which obstructs the convective flow of drug to tumour cells ${ }^{34}$.

Recently, studies of chitin and chitosan have been concentrated on their bioactivities, such as antitumor, immuno-enhancing, enhanced protection against certain pathogens infection in mice, antifungal and antimicrobial activition. Unlike usual functional polysaccharides, chitin and chitosan of smaller molecular weight exhibit the activities in in-vivo systems which are produced by hydrolysis with enzymes such as chitinases or chitosanases. The antitumor effects of $\mathrm{N}$-acetylchitohexaose (hexamer of chitin oligosaccharide) and chitohexaose (hexamer of chitosan oligosaccharide) were observed], while the protective effect of $\mathrm{N}$-acetylchitohexaose against Listeria monocytogenes infection in mice was examined ${ }^{35}$.

Furthermore, studies on the antitumor activity of chitin, chitosan, and their derivatives revealed that partially deacetylated chitin (especially $70 \%$ deacetylated chitin) and carboxymethyl chitin (CMchitin) with an adequate degree of substitute (especially 0.80) were effective towards various tumor cells. Some reports further revealed that oligomers with small molecular sizes (at least hexamer or higher) possess antitumor activity, because of their potential immunological activities such as activation of peritoneal macrophages and stimulation of nonspecific host resistance ${ }^{36}$.

The antitumor activity of polysaccharides seems to be dependent on their molecular size rather than on their chemical structure. For example, schizophyllan and lentinan, polysaccharides of both B-glucan types, exhibit most activity within a range of 100 to $200 \mathrm{kDa}$, and no activity below $10 \mathrm{kDa}$. However, oligosaccharides as well as high molecular weight chitin or chitosan have been known to have antitumor activity. It was reported that hexa $N$-acetylchitohexaose and chitohexaose, chitin and chitosan oligosaccharides composed of a hexamer, had strong antitumor immunopotentiating function. They suggest that the antitumor mechanism of these hexose oligomers was to involve increased production of lymphokines, including interleukins 1 and $2^{37,38}$.

In contrast, it has been established that most polysaccharides do not have direct antitumor effect by chemotherapy, but rather exhibit an indirect effect via activation of the immune system. In particular, the hexamer of chitin or chitosan expresses an antitumor effect by stimulating the immune system, including mechanisms such as the defense functions of macrophages, polymorphonuclear leukocytes, cytotoxic $\mathrm{T}$, and natural killer cell activities through the induction of interleukins 1 and $2^{39,40}$.

\section{Antitumor activity of Chitosan nanoparticles}

Biological nanoparticles are mainly developed for drug delivery systems as an alternative to liposomal technology, in order to overcome the problems related to the stability of these vesicles in biological fluids and during the storage. Polymer nanoparticles from biodegradable and biocompatible polymers are good candidates for drug carrier to deliver the drugs, because they are expected to be adsorbed in an intact form in the gastrointestinal tract after oral administration.

Many drugs have problems of poor stability, water insolubility, low selectivity, high toxicity, side effects and so the drug carriers play a significant role in resolving these problems. Chitosan nanoparticles are the drug carriers with wide development potential and have the advantage of slow/controlled drug release, which improves drug solubility and stability, enhances efficacy, and reduces toxicity. Because of their small size, they are capable of passing through biological barriers in vivo (such as the blood-brain barrier) and delivering drugs to the lesion site to enhance efficacy. Modified nanoparticles also have other properties such as improved drug targeting. Positive charges of chitosan have selective adsorption and neutralizing effects on the tumor cell surface. As a drug carrier, it has a targeting function to liver, spleen, lung, and colon ${ }^{41}$. Doxorubicin-chitosan polymeric micelles had excellent drug-loading properties, were suitable for targeting the liver and spleen, and significantly reduced drug toxicity to the heart and kidney ${ }^{42}$.

\section{ANTIMICROBIAL ACTIVITY OF CHITOSAN}

In the past half century, synthetic petroleum-based polymers have been widely used in a variety of packaging materials but have become a major source of waste disposal problems due to their poor biodegradability. With increasing demand of consumers for high-quality foods and concerns about limited natural resources and the environment, the use of renewable resources to produce edible or biodegradable packaging materials that can improve product quality and reduce waste disposal problems are being explored. One of the approaches is to use renewable biopolymers such as polysaccharides, proteins, lipids, and their composites, derived from plant and animal resources ${ }^{43-}$ 46.

Chitin and chitosan in vitro show antibacterial and antiyeast activities. One of chitosan derivatives, i.e., Ncarboxybutyl chitosan, was tested against 298 cultures of different pathogenic microorganisms that showed bacteriostatic and bactericidal activities, and there were marked morphological alterations in treated microorganisms when examined by electron microscopy 47 . Conversely, growth inhibition and inactivation of mould and yeasts seem to depend on chitosan concentration, $\mathrm{pH}$, and temperature ${ }^{48}$.

The antimicrobial activity of chitosan varies depending on their physical properties (degree of deacetylation (DD), and molecular weight), solvent, microorganism species and source. The antimicrobial activity is reported to vary depending on the methods involved in preparation of different DD and molecular weight of chitosan ${ }^{49,50}$. The antimicrobial action of chitosan is influenced by intrinsic and extrinsic factors such as the type of chitosan (e.g., plain or derivative), degree of chitosan polymerization, host nutrient constituency, substrate chemical and/or nutrient composition, and environmental conditions such as substrate water activity ${ }^{51}$. In an extensive research on the antimicrobial 
activity of chitosan prepared from shrimp against $E$. coli, it was found that higher temperature andacidic $\mathrm{pH}$ of foods increased the bactericidal effect of chitosan ${ }^{52}$. The mechanism of chitosan antibacterial action involving a cross-linkage between polycations of chitosan ${ }^{53}$ and the anions on the bacterial surface that changes membrane permeability and has been approved as a food additive in Japan and Korea since 1983 and 1995 respectively ${ }^{54}$.

Chitosan is the second most plentiful natural biopolymer and is relatively cheap ${ }^{55}$. It has attracted considerable interest due to its biological properties, such as antimicrobial activity, antitumor activity, and immune enhancing effect. However, the antibacterial activity of chitosan is influenced by a number of factors, including the species of bacteria, concentration, $\mathrm{pH}$, solvent and molecular mass ${ }^{56}$. The proposed mechanism for its antimicrobial action is binding to the negatively charged bacterial cell wall, with consequent destabilization of the cell envelope and altered permeability, followed by attachment to DNA with inhibition of its replication ${ }^{57}$. Due to excellent antimicrobial property, chitosan film may be used in food packaging ${ }^{58}$. Recently, a chitosanstarch film has been prepared by using microwave treatment which may find potential application in food packaging. The recent review on antimicrobial and antioxidative activities of chitosans in food ${ }^{59}$ also expresses the hopefulness of the different findings of the researchers for further progress to improve microbial food safety and food quality.

Chitosan is a mucoadhesive polymer that is able to open tight junctions and allow the paracellular transport of molecules across mucosal delivery of vaccines. Chitosan microparticles and nanoparticles loaded with DNA plasmids were reported to induce protective immune responses in mice ${ }^{60,61}$.

\section{Antimicrobial activity of Chitosan nanoparticles}

Chitosan-Ag nanocomposite is one of the rare composite materials that is seen to possess a capability of being used as a biosensor as well as in the treatment of cancer as the chitosan present in the nanocomposite is very specific to the cancer cells. It prolongs the action of silver on the affected cells while preventing the normal cell from the effect of silver. One more advantage of this nanocomposite is that it is biodegradable, i.e., it can be degraded by the enzymes present in the body making it suitable for the treatment of cancer. Apart from the treatment of cancer, the nanocomposite also possesses good antimicrobial and biosensing activity.

Biodegradable nanoparticulate systems have received considerable attention as potential drug delivery vehicles. Chitosan (CS), a polysaccharide known to be a favorable pharmaceutical material because of its biocompatibility and biodegradability, forms an ideal hydrophilic carrier system ${ }^{62}$. Moreover, chitosan has been shown to be non-toxic and tissue compatible in a range of tests. Nanoparticles, which can be produced with a wide variety of polymers and nanotechnologies, have also been recently proposed as delivery systems for peptides and proteins through the pulmonary route ${ }^{63}$. In this respect, chitosan is a very attractive polysaccharide due to its reported low toxicity, biodegradability and mucoadhesivity ${ }^{64}$. In fact, chitosan has been demonstrated to induce low or absent toxicity in cell lines representative of the pulmonary route ${ }^{65-66}$.

Modern dressings are capable of delivering silver through a sustained-release mechanism. This helps to avoid toxicity and yet ensures delivery of a therapeutic dose of silver to the wound ${ }^{67}$. It has been shown that reducing the particle size of materials is an efficient and reliable tool for improving their actions; hence, silver nanoparticles in some modern dressings, such as Acticoat, aids in burns management ${ }^{68}$. The antimicrobial properties of silver-containing wound dressings have been studied by a microcalorimetric technique. The results showed that this kind of dressing has the capacity to kill common wound pathogens Staphylococcus aureus and Pseudomonas aeruginosa ${ }^{69}$. Different nano silver-coated barrier dressings were reported to exhibit antimicrobial activity and reduce infection in wounds ${ }^{70}$. The antibacterial activity of chitosan tripolyphosphate nanoparticles loaded with various metal ions was investigated and the results showed that antibacterial activity was enhanced by the loaded metal ions ${ }^{71}$. An earlier work showed that accumulation of silver nanoparticles in bacterial membrane caused a significant increase in membrane permeability, resulting in the death of the cell ${ }^{72}$.

\section{WOUND DRESSING APPLICATIONS}

Wound healing is the body's natural process of regenerating dermal and epidermal tissue. It is the process whereby the body restores the injured part to as near its normal condition as possible. Though wound healing takes place naturally on its own, some of complications like sepsis, disruption of tissue and skin layer, maggot's formation, extension of infection to adjacent and interior organs occur in major cases. To prevent extensive loss and damage to the tissue, skin grafting ${ }^{73}$ and biological dressings ${ }^{74}$ were developed. The ability of the skin to repair itself after a minor wound is remarkable, but when the damage is severe or occurs in large amounts of skin area, proper and immediate coverage of wound surface with an adequate dressing is needed to protect the wound and to accelerate wound healing. Ultimately the immediate wound coverage, temporary or permanent, is one of the principal goals of wound management. For this films made with biomaterials are becoming popular due to many advantages.

There is an increasing need to develop new biodegradable materials to be used in skin tissue engineering, wound cover or as dressings and barriermembranes, since there is a high demand for skin replacements and skin repair treatments. For instance, an ideal material to be use as a wound dressing should associate availability with minimal storage requirements, long shelf life, versatility and, biocompatible behavior ${ }^{75}$. Many polymeric membranes have been investigated for the purpose of wound covering on account its importance in the treatment of 
burns, prevention of post surgical adhesions and cosmetic surgery. These materials include Synthetic polymers like polyurethane, polyethylene, polylactides, polyglycolides, and polyacrylonitrile. However some of these polymers have disadvantages in such applications, i.e. poor biocompatibility and release of acidic degradation products ${ }^{76,77}$.

One alternative approach involves the use of biodegradable polymers from renewable resources, it including starch, collagen, gelatin, chitosan and proteins (soy protein, casein, silk fibroin and wheat), since these polymers are widely available in nature, and are biodegradable and non-toxic ${ }^{78-80}$. No single dressing is suitable for all types of wounds. Often a number of different types of dressings will be used during the healing process of a single wound. Dressings should perform one or more of the following functions:

- Maintain a moist environment at the wound/dressing interface

- Absorb excess exudates without leakage to the surface of the dressing

- Provide bacterial protection

- Allow gaseous and fluid exchange

- Absorb wound odor

- Be non-adherent to the wound and easily removed without trauma

- Be non-toxic, non-allergenic and non-sensitizing (to both patient and medical staff)

- Sterile

Natural polymers when used as drug delivery carriers, they are degraded into biologically accepted compounds, often through the process of hydrolysis, which leave the incorporated medications behind. The major advantages of natural polymers are good cytocompatibility, biodegradable and do not require any surgery for removal of polymers ${ }^{81}$.

Chitosan is a biopolymer that has been well known as being able to accelerate the wound healing ${ }^{82}$. It was reported that chitosan stimulated the migration of poly morph nuclear (PMN) as well as mononuclear cells and accelerate the re-epitheliaization and normal skin regeneration ${ }^{83}$. Chitosan has antibacterial activity against a broad range of bacteria including gram negative and gram positive bacteria. The amine group of chitosan play pivotal role in the antibacterial mechanism of chitosan.

\section{Wound dressing applications of Chitosan based bioactive composites}

Silver has been used in the clinical setting as an antimicrobial for over a century, and silver nitrate is still a common antimicrobial used in the treatment of chronic wounds. Silver is effective against a broad range of aerobic, anaerobic, Gram-negative and Gram-positive bacteria, yeast, filamentous fungi and viruses ${ }^{84,85}$.

Cellulose is an interesting material for wound dressing since it can control wound exudates and can provide moist environment to a wound resulting in better wound healing. However, Cellulose itself has no antimicrobial activity to prevent wound infection. To achieve an antimicrobial activity, in this work silver nanoparticles were impregnated into Cellulose through the reduction mechanism by immersing Cellulose-Chitosan composite in the reduced silver nitrate solution. Biological dressings like, chitosan films ${ }^{86}$ and application of silver nanoparticles are popular for quicker wound healing. These polymers when used in combination such as chitosancellulose-silver nanoparticle had shown better results, than when used alone.

Ultimately the immediate wound coverage whether it is temporary or permanent, is one of the principal goals of wound management. For this films made with biomaterials are becoming popular due to many advantages. Impaired wound healing due to infections and other above mentioned complications spurred the search for drug loaded films. The drug loaded films are prepared by incorporating drugs like antibacterial and antibiotics in the films. The drug loaded films act as barrier to micro-organisms when applied on to wound and thus prevent secondary infections to augment the process of wound healing by stimulating wound healing environment. Therefore, drug loaded film is more useful to avoid secondary infections on the wound for fast wound healing. The wound healing property of chitosan film was improved by addition of other polymers. Thus, the present research work concentrated on the preparation and evaluation of composite films made with chitosan-cellulose-silver nanoparticle to ascertain the applicability of prepared combination for wound management. Moreover these findings are not yet reported in wound management so far. Chitosan, Cellulose-Silver Nanoparticle combination shows many advantages when used in other preparations like sponges, scaffolds etc. This combination also has good compatibility ${ }^{87}$.

An important aspect of materials used as wound dressings is their antimicrobial activities ${ }^{88}$. It has been proposed that interactions between positively charged chitosan molecules and negatively charged microbial cell membranes lead to the disruption of the microbial membrane and subsequently the leakage of proteinaceous and other intracellular constituents ${ }^{89-92}$. At lower concentrations $(<0.2 \mathrm{mg} / \mathrm{mL})$, the polycationic chitosan binds to the negatively charged bacterial surface to cause agglutination, while at higher concentrations, the larger number of positive charges impart a net positive charge to the bacterial surfaces to keep them in suspension ${ }^{90-91}$. It has also been proposed that chitosan interacts with the membrane of the cell to alter cell permeability ${ }^{92,93}$. Studies using fluorescent probes, 1-N-phenylnaphthylamine, nile red and propidium iodide, and field emission scanning electron microscopy suggested that chitosan-arginine's antibacterial activity is at least in part due to its interaction with the cell membrane, in which it increases membrane permeability ${ }^{93}$.

The antibacterial activities of chitosan and chitosan oligomers were compared against both gram-negative and gram-positive bacteria ${ }^{94}$. Chitosan showed higher antibacterial activities than chitosan oligomers and markedly inhibited the growth of most bacteria tested, 
although inhibitory effects differed with molecular weights of chitosan and the particular bacterium. Chitosan generally showed stronger bactericidal effects with gram-positive bacteria than with gram-negative bacteria in the presence of $0.1 \%$ chitosan. As a chitosan solvent, $1 \%$ acetic acid was effective in inhibiting the growth of most of the bacteria tested, except for lactic acid bacteria that were more effectively suppressed with $1 \%$ lactic or formic acids. The antimicrobial mode of action of chitosan was investigated using a combination of approaches. It was found that chitosan exhibited a dose-dependent growth-inhibitory effect. A simultaneous permeabilization of the cell membrane to small cellular components, coupled with a significant membrane depolarization, was detected. A concomitant interference with cell wall biosynthesis was not observed. Chitosan treatment of 22 Staphylococcus simulans cells did not give rise to cell wall lysis; the cell membrane also remained intact. The antimicrobial efficacy of $N$-carboxybutyl chitosan was tested, which was prepared from crustacean chitosan $(\mathrm{DDA}=73 \%)$, against 298 strains of gram-positive and gram-negative pathogens and Candida spp. ${ }^{95}$. It was found that $N$ carboxybutyl chitosan was particularly active against Candida and gram-positive bacteria. The antifungal activities of water-soluble low- and high-molecular weight chitosan hydrochloride, carboxymethyl chitosan, chitosan oligosaccharide, and N-acetyl-D-glucosamine against Candida albicans, Candida krusei, and Candida glabrata were studied ${ }^{96}$. The investigators observed a concentration-dependent antifungal activity of low- and high-molecular-weight chitosan hydrochloride against the fungal species in acid medium. In addition, the investigators found an influence of molecular weight on the antifungal activity: a low-molecular weight was associated with low antifungal activity. Another interesting fact was the low activity of carboxymethyl chitosan against the fungal species.

Chitosan-Nanofiber mats were prepared and evaluated as wound dressing for IIIa- and IIIb-degree burns. The results showed that chitosan-Nanofiber dressings provided effective absorption of exudates, ventilation of the wound, protection from infections, and stimulation of the process of skin tissue regeneration. Degradation of these materials prevented mechanical damage to the wound during removal.

A green route was described to produce antibacterial nanofiber mats loaded with silver nanoparticles (AgNPs, $25 \mathrm{~nm}$ diameters) enveloped in chitosan after reduction with glucose. The results showed superior properties and synergistic antibacterial effects by combining chitosan with Ag-NPs ${ }^{97}$. Gomes et al. performed a study in order to compare the performance of electrospun nanofiber mats from three different polymers concerning cell-scaffold interaction and wound healing promotion.

\section{CHITOSAN AS PRESERVATIVE}

Postharvest fruit and vegetable are living organisms, undertaking metabolism ceaselessly. Their character such as nutrition, favor, and appearance deteriorated during the process of storage and transportation owing to water loss, browning, decay, and so on ${ }^{98,99}$. Thus, the commercial value also decreases and many damages are caused to producer. To extend the shelf life of postharvest fruit and vegetable, some effective measures including low temperature, modified atmosphere packaging, irradiation and coating, have been applied 100-102

Packaging materials provide a means to preserve, protect, merchandise, market and distribute foods. They play a significant role in how these products reach the consumers in a safe and wholesome form without compromising quality. The relationship between the food and the packaging material continuously interact and contribute to changes that can occur over time in these products. It is therefore important that several factors are considered when choosing the right package for a particular food product.

In those measures, edible coating is one of promising methods because of its particular properties, which could avoid moisture loss and aromas loss, and inhibit the oxygen penetration to the plant tissue or microbial growth. In addition, edible coating is convenient and conforms to food safety ${ }^{103}$. Many materials such as polysaccharides, proteins, essential oils, may economically serve as edible coatings ${ }^{104-106}$.

Chitosan has strong antimicrobial and antifungal activities that could effectively control fruit decay ${ }^{107}$. It could easily form coating on fruit and vegetable, and the respiration rate of fruit and vegetable was reduced by adjusting the permeability of carbon dioxide and oxygen 108. Considering the superior properties of chitosan, it has been successfully used in many postharvest fruits and vegetables, such as grape, berry, jujube and freshcut lotus root ${ }^{109-111}$

Though chitosan coating has many advantages to the preservation of postharvest fruit and vegetable, as for specific fruit or vegetable, single chitosan coating sometimes demonstrates a certain defect, which includes limited inhibition to especial microorganism that leads fruit to decay, and poor coating structure to adjust the permeability of carbon dioxide and oxygen ${ }^{112}$. To effectively apply the chitosan coating, the chitosan was combined with other substances. In addition, the single chitosan coating was often combined with physical methods such as short heating, short gas fumigation, modified atmosphere packaging, and so on ${ }^{113}$.

Chitosan has good film forming performance and excellent biocompatibility, and is also safe and nontoxic. It has broad application in fruit and vegetable preservation ${ }^{114}$. Zinc, the IIB group transition metal element in the fourth cycle, is apt to form coordination bond with hydroxyl functional groups. It is associated with biological auxin synthesis and has important physiological functions to human body ${ }^{115}$. Cerium belonging to rare earth elements has many unique properties in biology, but its safety effect remains to be further studied ${ }^{116}$. It was found that chitosan-cerium compound coating could destroy $\mathrm{P}=\mathrm{O}$ bond and degrade organophosphorus pesticide residues ${ }^{117}$. 
The cerium or zinc composite coating all showed certain positive preserving effect to cherry tomato compared with single chitosan coating. As for the soluble solids, SOD and POD activities and the preservation of vitamin $\mathrm{C}$, the effect of chitosan-zinc acetate composite coating was slightly superior to that of chitosan-cerium acetate 118 .

Most fresh fruits and vegetables contain from 65\%-95\% water when harvested. When the harvested produce loses $5 \%$ or $10 \%$ of its fresh weight, it begins to wilt and soon becomes unusable. To keep water loss from fresh produce as low as possible, it must be kept in a moist atmosphere ${ }^{119}$. Tomato (Lycopersicume sculentum) is a warm-season crop; it ranked the highest in a comparison of crops in their contribution of nutrients to the diet. Water comprises $90 \%$ of the fresh weight of tomato fruit; and the fruit size is influenced by the availability of water to the plant. The large amount of water also makes the fruit perishable ${ }^{120}$.Many researchers have demonstrated that hot water treatment between $35^{\circ} \mathrm{C}$ and $63^{\circ} \mathrm{C}$ effectively inhibits ethylene production, delays ripening ${ }^{121}$, and reduces the water loss of fruits during storage.

Edible films are defined as a thin layer of material which can be consumed and provides a barrier to moisture, oxygen and solute movement for the food. The material can be a complete food coating or can be disposed as a continuous layer between food components ${ }^{122}$. Edible films can be formed as food coatings and free-standing films, and have the potential to be used with food as gas aroma barrier ${ }^{123}$. However, technical information is still needed to develop films for food application ${ }^{124}$. Edible films and coatings have received considerable attention in recent years because of their advantages over synthetic films. The main advantage of edible films over traditional synthetics is that they can be consumed with the packaged products. There is no package to dispose even if the films are not consumed they could still contribute to the reduction of environmental pollution. The films are produced exclusively from renewable, edible ingredients and therefore are anticipated to degrade more readily than polymeric materials. The films can enhance the organo-leptic properties of packaged foods provided they contain various components (flavorings, colorings, sweeteners). The films can be used for individual packaging of small portions of food, particularly products that currently are not individually packaged for practical reasons such as pears, beans, nuts and strawberries.

The films can be applied inside heterogeneous foods at the interfaces between different layers of components. They can be tailored to prevent deteriorative intercomponent moisture and solute migration in foods such as pizzas, pies and candies. The films can function as carriers for antimicrobial and antioxidant agents. In a similar application they can also be used on the surface of food to control the diffusion rate of preservative substances from the surface to the interior of the food. Another possible application for edible films could be their use in multilayer food packaging materials together with non edible films. In this case, the edible films would be the internal layers in direct contact with food materials. Production of edible films causes less waste and pollution, however, their permeability and mechanical properties are generally poorer than synthetic films ${ }^{123}$. Extensive research is needed on the development of new materials, methods of films formation, methods to improve film properties and the potential applications.

\section{Classification of edible films and coatings}

Edible films can be produced from materials with film forming ability. During manufacturing, film materials must be dispersed and dissolved in a solvent such as water, alcohol or mixture of water and alcohol or a mixture of other solvents. Plasticizers, antimicrobial agents, colors or flavors can be added in this process. Adjusting the $\mathrm{pH}$ and/or heating the solutions may be done for the specific polymer to facilitate dispersion. Film solution is then casted and dried at a desired temperature and relative humidity to obtain freestanding films.

In food applications, film solutions could be applied to food by several methods such as dipping, spraying, brushing and panning followed by drying. Components used for the preparation of edible films can be classified into three categories: hydrocolloids (such as proteins, polysaccharides, and alginate), lipids (such as fatty acids, acyl-glycerol, and waxes) and composites ${ }^{124}$.

Edible films and coatings can be used to help in the preservation of fruit and vegetables because they provide a partial barrier to moisture, $\mathrm{O}_{2}$ and $\mathrm{CO}_{2}$ also improving mechanical handling properties, carrying additives, avoiding volatiles loss and even contributing to the production of aroma volatiles ${ }^{125}$.This environment friendly technology wraps the film closely around the fruit preventing respiration and transpiration, thus slowing down senescence. Studies have shown that these films can be incorporated with nutrients or preservatives and are functional in various ways. With the demand for more natural foods, biopreservatives are being added to the films making it more wholesome for consumers ${ }^{126}$. Due to its unique physicochemical properties, Chitosans has been successfully used as food wraps, and maintains the quality of postharvest fruits and vegetables fruit ${ }^{127}$. Previous studies indicated that chitosans coating had the potential to prolong storage life and control decay of many fruits, such as strawberry, peach, table grape, apple and mango ${ }^{128}$.

\section{Chitosan Nanoparticles as preservatives}

Promising results and applications are already being developed in the areas of nutrient delivery systems through bioactive nanoencapsulation, biosensors to detect and quantify pathogens organic compounds, other chemicals and food composition alteration, and even edible film to preserve fruit or vegetables ${ }^{129}$.Consequently, natural biopolymer-based nanocomposite packaging materials with bio-functional properties have a huge potential for application in the active food packaging industry ${ }^{130}$. 
Chitosan - Ag nanocomposite is one of the rare composite materials that are seen to possess a capability of being used as a biosensor as well as in the treatment of cancer as the chitosan present in the nanocomposite is very specific to the cancer cells. It prolongs the action of silver on the affected cells while preventing the normal cell from the effect of silver. One more advantage of this nanocomposite is that it is biodegradable, i.e., it can be degraded by the enzymes present in the body making it suitable for the treatment of cancer. Apart from the

\section{REFERENCES}

1. Shahidi, F, Abuzaytoun, R, Adv. Food Nutr. Res, 2005, 49, 93-135.

2. Tharanathan, R.N, Kittur, F.S, Crit. Rev. Food. Sci. Nutr ,2003, 43,61-87.

3. San-Lang Wang, Tzu-Yin Lin, Yue-Horng Yen, Hui-Fen Liao and Yu-Jen Chen, Carbohydr. Res, 2006, 341, 2507-2515.

4. Mathur NK, Narang CK, J. Chem. Educ,1990, 67, 938-42.

5. Pradip Kumar Dutta, Joydeep Dutta and V S Tripathi, J. Sc. Ind. Res, 2004, 63, 20-31.

6. Kumar M. N. V. R, React. Funct . Polym , 2000, 46(1), 1-27.

7. No H. K. \& Lee, M. Y, J Korean Soc Food Nutr, 1995, 24, 105-113.

8. Lee, H. Y, Kim S. M, Kim, J. Y, Youn, S. K, Choi, J. S, Park, S. M, J Korean Soc Food Nutr, 2002, 31:445-450.

9. Chung Y.Ch., C.Y Chen , Bioresour. Technol., 2007, 99, 2806-2814.

10.Nagahama H, Kashiki T, Nwe N, Jayakumar R, Furuike T. and Tamura H,Carbohydr. Polym, 2007, 73,456-463.

11. Ta H.T, Dass C.R, Dunstan D.E. J. Control. Rel., 2008, 126, 205 216.

12. Harish Prashanth K.V, Tharanathan R.N, Trends Food Sci. Technol., 2007, 18,117-131.

13. Zahed Hossain, Asaduzzaman, M.A. Kashem, Bazlul Karim Akanda, S.K. Roy and Shahidul Islam, Bangladesh J. Sc. Ind. Res., 2005, 40(3-4), 163-168.

14. Hirano S, Biotechnology Annu. Rev., 1996, 2, 235-238.

15. Ng C.H, Hein S. Chandrakrachang S. \& Stevens W. F., J. Biomed Mater. Res., Part B, 2006, 76B (1),155-160.

16. Andrade, Vânia Sousa; Barros Neto, Benício de; Fukushima Kazutaka and Campos-Takaki, Galba Maria. Effect of medium components and time of cultivation on chitin production by Mucor circinelloides (Mucor javanicus IFO 4570) - A factorial study. Revista Iberoamericana de Micología, 2003, 20,149-153.

17. Synowiecki, Józef and Al-Khatteb, Nadia Ali Abdul. Production, properties, and some new applications of chitin and its derivatives. Critical Reviews in Food Science and Nutrition, 2003, 43(2),145 171.

18. Franco, Luciana de Oliveira; Stamford, Thayza Christina Montenegro; Stamford, Newton Pereira and Campos-Takaki, Galba Maria de. Cunningamella elegans (IFM 46109) como fonte de quitina e quitosana. Revista Analytica, 2005, 4(14), 40-44.

19. Tan, Su Ching Tan, Teck Koon; Wong, Sek Man and Khor, Eugene. The Chitosan yield of Zygomycetes at their optimum harvesting time, Carbohydrate Polymers, 1996, 30(4), 239-242.

20. Pochanavanich, P. and Suntornsuk, W. Fungal chitosan production and its characterization, Letters in Applied Microbiology, 2002, 35(1), 17-21.

21. Synowiecki, Józef and Al-Khatteb, Nadia Ali Abdul. Production, properties, and some new applications of chitin and its derivatives, Critical Reviews in Food Science and Nutrition, 2003, 43(2), 145 171.

22. Synowiecki, Józef and Al-Khatteb, Nadia Ali Abdul. Mycelia of Mucor rouxii as a source of chitin and chitosan, Food Chemistry, 1997, 60(4), 605-610.

23. Nemtsev, S.V.; Zueva, O. Yu; Khismatullin, M.R.; Albulov, A.I. and Varlamov, V.P. Isolation of Chitin and Chitosan from honeybees. Applied Biochemistry and Microbiology, 2004, 40(1), 39-43.

24. Andrade, V.S, Neto, B.B, Souza, W, Campos-Takaki, G.M. A factorial designs analysis of chitin production by Cunninghamella elegans. Canadian Journal of Microbiology, 2000, 46(11), 1042 1045 . treatment of cancer, the nanocomposite also possesses good antimicrobial and bio sensing activity ${ }^{131}$.

Searching for new therapeutic agents capable to work against resistant bacterial strains is one of the most important challenges for nowadays science. Application of nanotechnology in creating new biomaterials provides new solutions mainly because of small dimensions of the created systems. One of the most effective and promising materials are nanocomposites based on silver nanoparticles (AgNPs) and chitosan ${ }^{132}$.
25. Amorim, Rosa Valéria da Silva; De Souza, Wanderley; Fukushima, Kazutaka and Campos-Takaki, Galba Maria. Faster chitosan production by Mucoralean strains in submerged culture. Brazilian Journal of Microbiology, 2001,32(1), 20-23

26. Nadarajah, K.; Kader, J.; Mazmira, Mohd and Paul, D.C. Production of chitosan by fungi. Pakistan Journal of Biological Sciences, 2001, 4(3), 263-265

27. Zhou, K., Xia, W., Zhang, C., \& Yu, L. In vitro binding of bile acids and triglycerides by selected chitosan preparations and their physicochemical properties. LWT- Food Science and Technology, 2006, 39,1087-1092.

28. Liao F. H, Shieh, M. J, Chang, N. C, Chien, Y. W. Chitosan supplementation lowers serum lipids and maintains normal calcium, magnesium, and iron status in hyperlipidemic patients. Nutrition Research, 2007, 27(3),146-151.

29. Xia, W. S. (2003). Physiological activities of chitosan and its application in functiona foods. Journal of Chinese Institute of Food Science and Technology, 2003, 3(1),77-81.

30. Park, J. H., Saravanakumar, G. S., Kim, K. Y., \& Kwon, C.Targeted delivery of low molecular drugs using chitosan and its derivatives. Advanced Drug Delivery Reviews, 2010, 62(1), 28-41.

31.Bravo-Osuna I, Millotti, G, Vauthier, C, \& Ponchel, G. (2007). In vitro evaluation of calcium binding capacity of chitosan and thiolated chitosan poly (isobutyl cyanoacrylate) - core-shell nanoparticles, International Journal of Pharmaceutics, 2007, 338(1-2), 284-290.

32. Erkki Ruoslahti, Sangeeta N Bhatia, Michael J Sailor. Targeting of drugs and nanoparticles to tumors, Journal of cell biology, 2010 188(6), 759

33. Jiao PF, Zhou HY, Chen LX, Yan B. Cancer-targeting multifunctionalized gold nanoparticles in imaging and therapy, Curr Med Chem. 2011,18(14), 2086-102.

34. Vivek Kumar Gupta, et al. Nanoparticle Formulation for Hydrophilic \& Hydrophobic Drugs. Int. J. Res. Pharm. Sci., 2010, 1(2), 163-169.

35. Nishimura, S., N. Nishi, S. Tokura, K. Nishimura, and I. Azuma. 1986. Bioactive chitin derivatives. Activation of mouse-peritoneal macrophages by O-(carboxymethyl) chitins, Carbohydr. Res,.146, 251-258.

36. Shimojoh, M., K. Masaki, K. Kurita, and L. Fukoshima. Bactericidal effects of chitosan from squid pens on Oral Streptococci Nippon Nogeikagaku Kaishi, 1996; 70, 787-792.

37. Sudharshan, N. R., D. G. Hoover, and D. Knorr. Antibacterial action of chitosan. Food Biotechnol, 1992; 6, 257-272.

38. Blaschek, W., J. Kasbauer, J. Kraus, and G. Franz. Pythium aphanidermatum : Culture, cell wall composition, and isolation and structure of antitumor storage and solubilized cell-wall $(1 \rightarrow 3),(1 \rightarrow 6) B$-D-glucans. Carbohydr.Res, 1992, 231, 293-307.

39. Bohn, J. A. and J. N. BeMiller. $(1 \rightarrow 3$ ) B -D-glucans as biological response modifiers: A review of structurefunctional activity relationships, Carbohydr. Polym, 1995, 28:3-14.

40. Tsukada, K., T. Matsumoto, K. Aizawa, A. Tokoro, R.-S. Naruse, S. Suzuki, and M. Suzuki.. Antimetastatic and growth-inhibitory effects of $\mathrm{N}$-acetylchitohexaose in mice bearing Lewis lung carcinoma., Jpn. J. Cancer Res, 1990, 81,259-265.

41. Park K, Kim J, Nam Y, et al. Effect of polymer molecular weight on the tumor targeting characteristics of self-assembled glycol chitosan nanoparticles, J Control Release., 2007, 122(3), 305-314.

42. Xu XY, Zhou JP, Li L. Preparation of doxorubicin-loaded chitosan polymeric micelle and study on its tissue biodistribution in mice, Acta Pharm Sin., 2008, 43(7),743-748. 
43. Kester, J. J.; Fennema, O. R. Edible films and coatings: a review. Food Technol., 1986, 40 (12), 47-59.

44. Guilbert, S. Technology and application of edible protective films In Food Packaging and PreserVation, Theory and Practice; Mathlouthi M., Ed.; Elsevier Applied Science Publishing: London, U.K., 1986, pp 371-394.

45. Debeaufort, F, Quezada-Gallo, J.-A Voilley, A. Edible films and coatings: tomorrow's packagings: a review. Crit. Rev. Food Sci. 1998, 38, 299-313.

46. Krochta, J. M.; De Mulder-Johnston, C. Edible and biodegradable polymer films: challenges and opportunities. Food Technol., 1997, 51 (2), 61-74

47. Koide S.S. Chitin-Chitosan: properties, Benefits and Risks, Nutrition Research., 1998, 18(6), 1091-1101.

48. Rout S. K. Physicochemical, Functional, and Spectroscopic analysis of crawfish chitin and chitosan as affected by process modification. Dissertation, 2001.

49. Qin CQ, Li HR, Xiao Q, Liu Y, Zhu JC, Du YM. Water solubility of chitosan and its antimicrobial activity, Carbohydrate Polymers, 2006, 63:367-374.

50. Chen Y M, Chung YC, Wang LW, Chen KT, Li SY. Antibacterial activity of chitosan- based matrixes on oral pathogens. Health A Tox Hazard Subst, Environ Eng. J.Environ Sci., 2002, 37, 13791390.

51.Cuero, R.G. Antimicrobial action of exogenous chitosan, EXS., 1999. 87, 315-333.

52. Del Blanco L.F., Rodriguez M.S., Schulz P.C., Agullo E. Influence of the deacetylation degree on chitosan emulsification properties,Colloid Polymer Science, 1999, 277, 1087-1092.

53. Abu Tareq, M. Masihul Alam, Md. Salim Raza, Md. Tanvir Sarwar, Z. Fardous, Alamgir Z. Chowdhury, Sabir Hossain. Comparative study of antibacterial activity of chitin and chemically treated chitosan prepared from shrimp (Macrobrachium rosenbergii) shel waste International Journal of Virology Microbiology (JVM) Vol. 2013, 1-9.

54. Weiner M. L. An overview of the regulatory status and of the safety of chitin and chitosan as food and pharmaceutical ingredients. In: Brine, C.J., Sandford, P.A., Zikakis, J.P. (Eds.).1992.

55. Dutta P K, Dutta J, Chattopadhyaya M C and Tripathi V S J., Polym. Mater, 2004, 21, 321

56. Hernández-Lauzardo A N, Bautista-Baños S, Velázquez-del Valle M G, Méndez-Montealvo M G, Sánchez-Rivera M M and BelloPérez L A Carbohyd. Polym., 2008,73,541

57. Helander I M, Nurmiaho-Lassila E L, Ahvenainen R, Rhoades J and Roller S 2001 Int. J. Food Microbiol., 2001,71, 235

58. Tripathi S, Mehrotra G K and Dutta P K, Polymers, 2008, 093, 1

59. Friedman M and Juneja V K J. Food Prot., 2010, 73, 1737

60. Roy, K.; Mao, H. Q.; Huang, S. K.; Leong, K. W. Nature Med. 1999, 5, 387-391.

61.Kumar, M.; Behera, A. K.; Lockey, R. F.; Zhang, J.; Bhullar, G.; De La Cruz, C. P.; Chen, L. C.; Leong, K.W.; Huang, S. K.; Mohapatra, S. S. Hum. Gene Ther. 2002, 13,1415-1425.

62. J Kreuter. Infection, 1991,19: S224-S228.

63.MJ Alonso. Nanoparticulate drug carrier technology, in: S. Cohen, H. Bernstein (Eds.), Microparticulate systems for the Delivery of Proteins and Vaccines, Marcel Dekker, New York, 1996, 203 242.

64. Q Zhang, Z Shen, T Nagai. Int J Pharm, 2001, 218, 75-80.

65. Grenha B Seijo, C Remuñan-Lopez., Eur J Pharm Sci, 2005, 25,427-437.

66. S Hirano, H Seino, Y Akiyama, I Nonaka. Polym Mater Sci Eng, 1988, 59, 897-901.

67. Rai M, Yadav A, Gade A. Silver nanoparticles as a new generation of antimicrobials. Biotechnol Adv, 2009, 27, 76-83.

68. Son WK, Youk JH, Park WH. Antimicrobial cellulose acetate nanofibers containing silver nanoparticles, Carbohyd polym, 2006, 65,430-434.

69.O'Neill MA, Vine GJ, Bishop AH, Hadgraft J, Labetoulle C, Walker M, Bowler PG. Antimicrobial properties of silver-containing wound dressings: a microcalorimetric study, Int J Pharm 2003, 263, 61-68.

70.Supp AP, Neely AN, Supp DM, Warden GD, Boyce S. Evaluation of cytotoxicity and antimicrobial activity of Acticoat Burn Dressing for management of microbial contamination in cultured skin substitutes grafted to athymic mice, J Burn Care Rehabilitation, 2005, 26, 238-246.

71. Du WL, Niu SS, Xu YL, Xu ZR, Fan CL. Antibacterial activity of chitosan tripolyphosphate nanoparticles loaded with various metal ions, Carbohyd polym, 2009, 75, 385-389.
72. Kim JS, Kuk E, Yu KN.Antimicrobial effects of silver nanoparticles. Nanomedicine, 2007, 3, 95-101.

73. Anjaiah A, Haragopal V, Raghavender KBP and Chandra Sekhar EL, Effects of full thickness skin grafts and mesh skin grafts on granulating wounds in dogs: An experimental study. Cheiron, 2001, 30: 92-94

74. Varshney AC, Amresh K and Harpal S. Effect of various biostimulators on clinical wound healing in bovines, Ind Vet $\mathrm{J}$, 1988, 65, 436-439.

75. Khan T. A. and Peh K. K., Pham. Pharm. Sci., 2003; 6: 1-20.

76. Mi F.L., Wu. Y. B., Shyu S.S., Chao A.C., LAI. J.Y., SU. C.C., J. Membr. Sci., 2003, 5, 212-237.

77. Gunatilake P. A. and Adhikari R., Eur. Cells Mat., 2003, 5:1.

78. Bakos D., Koller J , in edited by Rui L. Reis and Daniel Cohn NATO Science Series, Kluwer Academic Publishers, (2001), 55.

79.Demirgoz D., Elvira C. Mao J.F, Cunha A.M, Piskin E. , Reis R.L., Polym. Degrad. Stabil., 2000, 70,161.

80.Silva R.M, Silva G.A, Coutinho O.P, Mano J.F., Reis R.L, J. Mater. Sci.- Mater. Med. 14, 2003, 127-135.

81. Shi C, Zhu Y, Ran X, Wang M, Su Y, Cheng T. Therapeutic potential of Chitosan and its derivatives in regenerative medicine, J Surg res.,2009,133,185-192

82. Kojima K., Okamoto Y., Miyatake K., Kitamura Y., Minami S., Carbohydrate Polymers, 1998, 37,109-114.

83.Usami Y., Okamoto Y., Minami S., Matsuhashi A., Kumazawa N.H., Tanioka S., Journal of Veterinary Medical Science, 1994, 56,761768

84. Wright J.B., Lam K., Hanson D. and Burrell R.E.,(1999). .Am J Inf Cont., 27, 344.

85. Grier N, Silver and its compounds. In: Block SS, editor. Disinfection, Sterilization and Preservation, 3rd ed. 1983. Philadelphia, PA: Lea \& Febiger

86. In-Yong K., Seo S.J., Moon H.S., Yoo M.K., In- Young P., Kim B.C. and Cho C.S. Chitosan and its derivatives for tissue engineering applications. Biotechnol Adv., 2008, 26, 1-21.

87. Anjaiah A., Haragopal V., Raghavender K.B.P. and Chandra Sekhar E.L. Effects of full thickness skin grafts and mesh skin grafts on granulating wounds in dogs: An experimental study. Cheiron., 2001, 30, 92-94.

88. Azuma, K.; Ifuku, S.; Osaki, T.; Okamoto, Y.; Minami, S. Preparation and Biomedical Applications of Chitin and Chitosan Nanofibers., J. Biomed. Nanotechnol., 2014, 10, 2891-2920.

89. Li, P.; Poon, Y.F.; Li, W.; Zhu, H.Y.; Yeap, S.H.; Cao, Y.; Qi, X.; Zhou, C.; Lamrani, M.; Beuerman, R.W.; et al. A polycationic antimicrobial and biocompatible hydrogel with microbe membrane suctioning ability, Nature Mater, 2011,10, 149-156.

90. Kong, M.; Chen, X.G.; Xing, K.; Park, H. Antimicrobial properties of chitosan and mode of action: a state of the art review, Int. J. Food Microbiol, 2010, 144:51-63.

91. Andres, Y.; Giraud, L.; Gerente, C.; Le Cloirec, P. Antibacterial effects of chitosan powder: Mechanisms of action, Environ. Technol., 2007, 28, 1357-1363.

92. Raafat, D.; von Bargen, K.; Haas, A.; Sahl, H.G. Insights into the mode of action of chitosan as an antibacterial compound, Appl. Environ. Microbiol., 2008, 74, 3764-3773.

93.Tang, H.; Zhang, P.; Kieft, T.L.; Ryan, S.J.; Baker, S.M.; Wiesmann, W.P.; Rogelj, S. Antibacterial action of a novel functionalized chitosan-arginine against Gram-negative bacteria, Acta Biomater, 2010, 6, 2562-2571.

94. No, H.K.; Park, N.Y.; Lee, S.H.; Meyers, S.P. Antibacterial activity of chitosans and chitosan oligomers with different molecular weights, Int. J. Food Microbiol, 2002, 74, 65-72.

95. Muzzarelli, R.; Tarsi, R.; Filippini, O.; Giovanetti, E.; Biagini, G.; Varaldo, P.E. Antimicrobial properties of N-carboxybutyl chitosan, Antimicrob. Agents Chemothe, 1990, 10, 2019-2023.

96.Seyfarth, F.; Schliemann, S.; Elsner, P.; Hipler, U.C. Antifungal effect of high- and low-molecular-weight chitosan hydrochloride, carboxymethyl chitosan, chitosan oligosaccharide and N-acetyl-Dglucosamine against Candida albicans, Candida krusei and Candida glabrata, Int. J. Pharmaceut. ,2008, 353, 139-148.

97. Abdelgawad, A.M.; Hudson, S.M.; Rojas, O.J. Antimicrobial wound dressing nanofiber mats from multicomponent (chitosan/silverNPs/polyvinyl alcohol) systems. Carbohydr Polym, 2014, 100, 166-178.

98. Gatto MA, Ippolito A, Linsalata V, Cascarano NA, Nigro F, et al., Activity of extracts from wild edible herbs against postharvest fungal diseases of fruit and vegetables. Postharvest Biol Tec, $2011,61,72-82$ 
99. Terry LA, Joyce DC (2004) Elicitors of induced disease resistance in postharvest horticultural crops: a brief review. Postharvest Biol Tec, 200, 32, 1-13.

100. Xanthopoulos G, Koronaki ED, Boudouvis AG, Mass transport analysis in perforation-mediated modified atmosphere packaging of strawberries. J Food Eng, 2012, 111:326-335.

101. Castagna A, Chiavaro E, Dall'asta C, Rinaldi M, Galaverna G, et al. Effect of postharvest UV-B irradiation on nutraceutical quality and physical properties of tomato fruits. Food Chem, 2013, 137, 151-158.

102. Sañudo MB, Siller-Cepeda J, Muy-Rangel D, Heredia JB Extending the shelf-life of bananas with 1-methylcyclopropene and a chitosan-based edible coating. J Sci Food Agr 2009, 89, 2343-2349.

103. Mantilla N, Castell-Perez ME, Gomes C, Moreira RG Multilayered antimicrobial edible coating and its effect on quality and shelf-life of fresh-cut pineapple (Ananas comosus). Food Sci Techno, 2013, 51, 37-43.

104. Vanzela ESL, Nascimento PD, Fontes EAF, Mauro MA, Kimura $M$ Edible coatings from native and modified starches retain carotenoids in pumpkin during drying. Food Sci Technol, 2013, 50, 420-425.

105. Lima MA, Cerqueira MA, Souza BWS, Santos ECM, Teixeira JA et al. New edible coatings composed of galactomannans and collagen blends to improve the postharvest quality of fruits Influence on fruits gas transfer rate. J Food Eng 2010, 97, 101109.

106. Santos NSD, Aguiar AJA, Oliveira CED, Sales CVD, Silva SDM, et al. Efficacy of the application of a coating composed of chitosan and Origanum vulgare L. essential oil to control Rhizopus stolonifer and Aspergillus niger in grapes (Vitis labrusca L.). Food Microbiol, 2012, 32, 345-353.

107. Aider M Chitosan application for active bio-based films production and potential in the food industry: Review. Food Sci TechnolLEB, 2010, 43, 837-842.

108. Elsabee MZ, Abdou ES, Chitosan based edible films and coatings: A review. Mater Sci Eng C Mater Biol Appl, 2013, 33, 1819. 1841 .

109.Perdones A, Sánchez-González L, Chiralt A, Vargas M Effect of chitosan-lemon essential oil coatings on storage-keeping quality of strawberry. Postharvest Biol Tec, 2012, 70, 32-41.

110. Yu YW, Zhang SY, Ren YZ, Li H, Zhang XN, et al. Jujube preservation using chitosan film with nano-silicon dioxide. J Food Eng, 2012, 113, 408-414.

111.Xing Y, Li X, Xu Q, Jiang YH, Yun J, et al. Effects of chitosanbased coating and modified atmosphere packaging (MAP) on browning and shelf life of fresh-cut lotus root (Nelumbo nucifera Gaerth). Innov Food Sci Emerg, 2010, 11, 684-689.

112. Ravi KMNV, A review of chitin and chitosan applications. React funct Polym, 2000, 46,1-27.

113.Shao XF, Tu K, Tu S, Tu J, A Combination of Heat Treatment and Chitosan Coating Delays Ripening and Reduces Decay in "Gala" Apple Fruit. J Food Quality, 2012, 35, 83-112.

114. Duan JL, Zhang SY, Application of chitosan based coating in fruit and vegetable preservation: A Review. J Food Process Technol, 2013, 4, 227.

115. Amarakoon D, Thavarajah D, McPhee K, et al, Iron-,zinc-, and magnesium-rich field peas (Pisum sativum L.) with naturally low phytic acid: A potential food-based solution to global micronutrient malnutrition.Journal of Food Composition and Analysis, 2012, 27(1), 8-13.

116. Cao R, Zhou Q, Advances in cellular toxicological effects of rare earths. Chinese Journal of Eco-Agriculture, 2007, 15(4), 180-184.

117. Wu H, Wang DF, Shi J, et al, Effect of the Complex of Zinc(II) and Cerium(IV) with Chitosan on the Preservation Quality and Degradation of Organophosphorus Pesticides in Chinese Jujube (Zizyphus jujuba Mill. cv. Dongzao). J. Agric. Food Chem. 2010, $58,5757-5762$.

118. Zhang Juan, Zhang Shaoying, Yu Youwei, Ren Yinzhe, Cherry tomato preservation using chitosan combined with zinc/cerium ion, International Journal of Nutrition and Food Sciences 2014, 3(2), 111-118

119. Elazar, R. Postharvest physiology, pathology and handling of fresh commodities. Lecture Notes. Department of Market Research.Ministry of Agriculture and Rural Development, 2004, Israel.

120. Jones, J. Tomato plant culture: in the field, greenhouse, and home garden. CRC Press. Boca Raton, 1999, FL 1-30.

121. Biggs, M. S., R. William, and A. Handa. Biological basis of hightemperature inhibition of ethylene biosynthesis in ripening tomato fruit. Journal of Plant Physiology, 1988; 72(2), 572-578.

122. Guilbert, S. Technology and application of edible protective films. In Mathlouthi, M. (Ed.), Food packaging and preservation, 1986; p. 371-394. London, UK: Elsevier Applied Science.

123. Kester, J. J. and Fennema, O. R., Edible films and coatings: A review. Food Technology, 1986, 40(12), 47-59.

124. Donhowe, I. G. and Fennema, O. R., The effects of plasticizers on crystallinity, permeability, and mechanical properties of methylcellulose films. Journal of Food Processing and Preservation, 1993, 17, 247-257

125. Olivas, GI, and G. V. Barbosa-Canovas. Edible coatings for freshcut fruits. Critical Reviews on Food Science and Nutrition, 2005 , 45 (7-8), 657-670.

126. Kader, A. A., Postharvest technology of horticultural crops (2nd Edition). UC Publication 3311.University of California, Division of Agriculture and Natural Resources,Oakland, 1992, California 94608.

127. Devlieghere, F., A. Vermeulen, and J. Debevere., Chitosan: antimicrobial activity, interactions with food components and applicability as a coating on fruit and vegetables. Food Microbiology, 2004, 21 (6), 703-714.

128. Chien, P. J., F. Sheu, and H. R. Lin. Coating citrus (Murcotttangor) fruit with low molecular weight chitosan increases postharvest quality and shelf life. Food Chemistry, 2007, 100 (3), 1160-1164.

129. Duran N and Marcato PD, Nanobiotechnology perspectives. Role of nanotechnology in the food industry: a review, International Journal of Food Science and Technology, 2012, 48 (6), 1127 1134

130. Rhim JW and Perry KW, Natural Biopolymer-Based Nanocomposite Films for Packaging Applications, Critical Reviews in Food Science and Nutrition, 2007, 47 (4), 411-433.

131. Govindan S, Nivethaa EA, Saravanan R, Narayanan V and Stephen ASynthesis and characterization of chitosan- silver nanocomposite, Applied Nanoscience, 2012, 2, 299-303.

132. Regiel A and Kyziol A Chitosan- silver nanocomposites - modern antibacterial materials. Chemik, 2012, 67 (8), 683- 692. 